\title{
CLASSIFICAÇÃO DE EVENTOS PLUVIOMÉTRICOS EXTREMOS EM ÁREA AFETADA POR PROCESSOS DE ARENIZAÇÃO NO SUDOESTE DO RIO GRANDE DO SUL
}

\author{
Andrey Luis Binda* \\ Universidade Federal da Fronteira Sul
}

\section{Roberto Verdum*}

Universidade Federal do Rio Grande do Sul

\begin{abstract}
Resumo: Areais são feições notáveis na paisagem dos campos da campanha gaúcha. Embora inicialmente tratadas como desertos, a gênese dos areais são antes decorrentes do clima úmido atual, principalmente da ação de chuvas torrenciais como elemento disparador dos processos de arenização. Esses processos são altamente dinâmicos no tempo e no espaço, de tal modo que os areais apresentam expansão/retração, dependendo, substancialmente, do regime de chuvas (excesso, redução ou ausência). Nesse sentido, visa-se, no presente trabalho apresentar a importância da classificação dos anos/meses-padrão como subsídio para o reconhecimento de eventos pluviométricos extremos, em área afetada por processos de arenização, no sudoeste do estado do Rio Grande do Sul. Os resultados apontam que os anos-padrão são categoricamente atrelados ao aumento do número de dias com chuva, que ensejam o aumento/redução dos totais anuais. Ao longo dos anos, notam-se sucessões de anos-padrão chuvosos/secos, caracterizando períodos marcadamente relacionados ao aumento/redução dos totais pluviométricos. Mensalmente, as chuvas também apresentam elevada variabilidade. Contudo, meses-padrão chuvosos e secos ocorreram em maior frequência, demonstrando que pode ocorrer intensificação nos processos de arenização. Isso ocorre quando um mês-padrão seco é sucedido por outro chuvoso, interferindo, sobretudo, na cobertura vegetal herbácea predominante sobre as formações superficiais e os solos no Pampa. Palavras-chave:
\end{abstract}

\section{EXTREME RAINFALL EVENTS CLASSIFICATION ON AREA AFFECTED BY SANDIZATION PROCESSES IN SOUTHWESTERN OF RIO GRANDE DO SUL STATE, BRAZIL}

Abstract: Sand spots are remarkable features in the landscape of the southern Brazil grasslands. Although initially treated as deserts, the genesis of the sand deposits is due to the current humid climate, mainly from the action of torrential rains as a triggering element of the sandization processes. These processes are highly dynamic in the time and the space scales, so that the sand deposits presents expansion/retraction, depending substantially on the rainfall regime (excess, reduction or absence). In this sense, the objective of this paper is to present the importance of the classification of the standard-years/months as a basis for the recognition of extreme rainfall events on an area affected by sandization processes in the southwestern of Rio Grande do Sul State, Brazil. The results indicate that the standard-years classification are categorically associated of the increase in the number of rainy days, which induce the increase/reduction of annual totals. Over the years, there have been successions of rainy/dry standard-years, characterizing periods markedly related to the increase/reduction of total precipitation. Rainfall also presents high variability on a monthly basis. However, rainy and dry standard-months occurred more frequently, demonstrating that intensification may occur in the sandization processes. This occurs when a dry standardmonth is followed by a rainy one, interfering mostly in the herbaceous vegetation on the surface formations and soils of grassland.

Keywords: standard-years classification; standard-months classification; rainy days; rainfall variability.

\section{CLASSIFICATION DES ÉVÉNEMENTS PLUVIOMÉTRIQUES EXTRÊMES DANS LA ZONE AFFECTÉE PAR LES PROCÉDÉS D'ARÉNISATION DANS LE SUD-OUEST DE RIO GRANDE DO SUL}

Résumé: Les sables sont des caractéris humide actuel, principalement à cause de l'action des pluies torrentielles comme déclencheur des processus d'arénisation. Ces processus sont très dynamiques dans le temps et dans l'espace, de telle sorte que les sables présentent une expansion/rétraction, en fonction, considérablement, du régime pluviométrique (excès, réduction ou absence). En ce sens là, le but de cet article est de présenter l'importance de classer les années/mois standard comme une subvention pour la reconnaissance des événements pluviométriques extrêmes, dans une zone affectée par des processus d'arénisation, dans le sud-ouest de l'État de Rio Grande do Sul. les résultats indiquent que les années standard sont catégoriquement connecté à l'augmentation du nombre de jours de pluie, ce qui rendre possible une augmentation/réduction des totaux annuels.Au fil des ans, des successions d'années standard pluvieuses/sèches ont été notées, caractérisant des périodes nettement liées à l'augmentation/la diminution des totaux pluviométriques. Mensuellement, les précipitations présentent également une grande variabilité. Cependant, les mois pluvieux et secs standard se sont produits plus fréquemment, ce qui montre que l'intensification des processus d'arénisation peut se produire. Cela se produit lorsqu'un mois sec standard est suivi d'un autre mois pluvieux, interférant principalement dans la végétation herbacée prédominante sur les formations superficielles et les sols de la Pampa. tiques notables du paysage rural de la campagne du Rio Grande do Sul. Cepandant initialement traitée comme un désert, la genèse des sables est plutôt grâce au climat

Mots clés: Années-standard; mois-standard; jours avec de la pluie; variabilité des précipitations

* Doutor em Geografia. Professor adjunto de Geografia da Universidade Federal da Fronteira Sul (UFFS). Av. Fernando Machado 108E, Centro - CEP: 89.802-112 - Chapecó/SC. ORCID: https://orcid. org/0000-0003-0381-6219. E-mail: abinda@uffs.edu.br

** Doutor em Geografia. Professor Titular do Departamento de Geografia da Universidade Federal do Rio Grande do Sul (UFRGS). Av. Bento Gonçalves, 9500 - Prédio $43136 / 216$ - Agronomia - CEP: 91.540-000 - Porto Alegre/RS. ORCID: https://orcid.org/0000-0002-0528-4343, E-mail: verdum@ufrgs.br 


\section{INTRODUÇÃO}

Exposições arenosas em meio às coxilhas sul-rio-grandense se destacam na paisagem dos campos da campanha gaúcha. Tratadas, inicialmente, como desertos e núcleos de desertificação, foram posteriormente, abordadas como oriundas de processos bem distintos daqueles que ocorrem em áreas áridas, semiáridas ou subúmidas secas. Suertegaray (1998) lança as bases científicas para elucidação da gênese dos areais, descrevendo que os processos de arenização, estão antes associados à abundância de água, principalmente, no papel das chuvas torrenciais (VERDUM, 1997).

Entende-se por processo de arenização o retrabalhamento contínuo de solos arenosos, inicialmente pela ação hídrica e, posteriormente, pela influência eólica. Pode-se discriminá-lo em três fases: a primeira, que consiste na formação de ravinas e de voçorocas pela ação do escoamento superficial durante episódios torrenciais de chuva; um segundo momento, que se caracteriza pela ampliação lateral e longitudinal da incisão; e um terceiro momento, em que esses processos hídricos expõem o solo e as formações superficiais quaternárias à deflação eólica, tanto pela coalescência das feições erosivas, como também pela existência de depósitos formados pelos cones de dejeção (SUERTEGARAY, 1998; SUERTEGARAY et al. 2001).

Suertegaray et al. (1996) demonstraram com base na análise de dados de sensoriamento remoto uma tendência de aumento dos focos de arenização num período de 50 anos para os municípios de São Francisco de Assis e Manoel Viana. Contudo, determinadas áreas mapeadas, inicialmente, como areais, foram recobertas pela vegetação campestre. Essa dinâmica de expansão/retração dos areais é algo, bastante comum. Inclusive, Freitas et al. (2009), assim como Verdum e Soares (2010) atestam a importância do regime de chuvas, tanto da influência de períodos de excesso, como também da redução e/ou ausência dos totais pluviométricos. Assim, torna-se necessário buscar metodologias que permitam expressar de modo quali-quantitativo a variabilidade das chuvas.

Partindo desse pressuposto, visa-se, no presente trabalho apresentar a importância da classificação dos anos/meses-padrão como subsídio para o reconhecimento de eventos pluviométricos extremos, em área afetada por processos de arenização, no sudoeste do estado do Rio Grande do Sul. Assim, espera-se que os resultados aqui apresentados corroborem com a assertiva do papel das chuvas (associado ao meio extremamente frágil em termos de cobertura vegetal, formações superficiais e solos) como elemento disparador dos processos superficiais associados à gênese dos areais.

\section{MATERIAIS E MÉTODO}

$\mathrm{Na}$ intenção de cumprir com o objetivo, fez-se uso de dados coletados na estação pluviométrica "Ponte do Miracatu" (código: 02955006) de responsabilidade da Agência Nacional das Águas (ANA) e operada pelo Serviço Geológico Brasileiro (CPRM), disponíveis no Sistema de Informações Hidrológicas (Hidroweb)' Instalada aproximadamente no centro da Bacia Hidrográfica do Arroio Miracatu (BHAM) e, administrativamente, no município de São Francisco de Assis/ RS (Figura 1), essa estação pluviométrica $\left(29^{\circ} 27^{\prime} 33^{\prime \prime}\right.$ $S$ e $55^{\circ} 17^{\prime} 28^{\prime \prime}$ ) encontra-se no flanco de uma coxilha, em altitude de cerca de $100 \mathrm{~m}$, nas proximidades da estrada antiga que liga a Manoel Viana/RS.

A série histórica selecionada de registros pluviais para o presente estudo compreende o período de 1970 a 2013, ou seja, 44 anos. Nesse lapso de tempo, entretanto, um total de 10 meses, distribuídos em quatro diferentes anos, apresentavam dados faltantes ou completamente sem registros. Devido a isso, procedeu-se ao preenchimento dessas falhas na intenção de se obter uma série completa e ininterrupta de precipitação. Para estimar o volume de chuva para cada um dos meses foram necessários dados de outras três estações pluviométricas. Enfatiza-se que essas estações pluviométricas também apresentavam falhas, muitas delas nos mesmos períodos daqueles observados para a "Ponte do Miracatu", justificando, assim, a necessidade de se utilizar as três estações pluviométricas para o completo preenchimento das falhas.

As estações pluviométricas utilizadas para essa tarefa foram: Jacaquá (código: 02955016), localizada no município de Alegrete/RS; Manoel Viana (código: 02955008), no município homônimo, e Passo Mariano Pinto (02956006), no município de Itaqui/RS (Figura 1). Todas essas estações pluviométricas são de responsabilidade da ANA e operadas pela CPRM. Destaca-se que as duas primeiras se encontram a aproximadamente 25 km da estação pluviométrica "Ponte do Miracatu", enquanto a última, mais distante, na casa de $75 \mathrm{~km}$. Salienta-se que foram testadas estações pluviométricas mais próximas, cujos dados foram, porém, descartados por apresentarem: coeficientes de determinação inapropriados, falhas nos mesmos meses ou por estarem instaladas em um contexto geomorfológico distinto (por exemplo, no compartimento de relevo mais elevado - planalto - , situado ao norte da área de estudo).

'Disponível em: <http://hidroweb.ana.gov.br/>. Acesso em: 11 nov. 2014. 


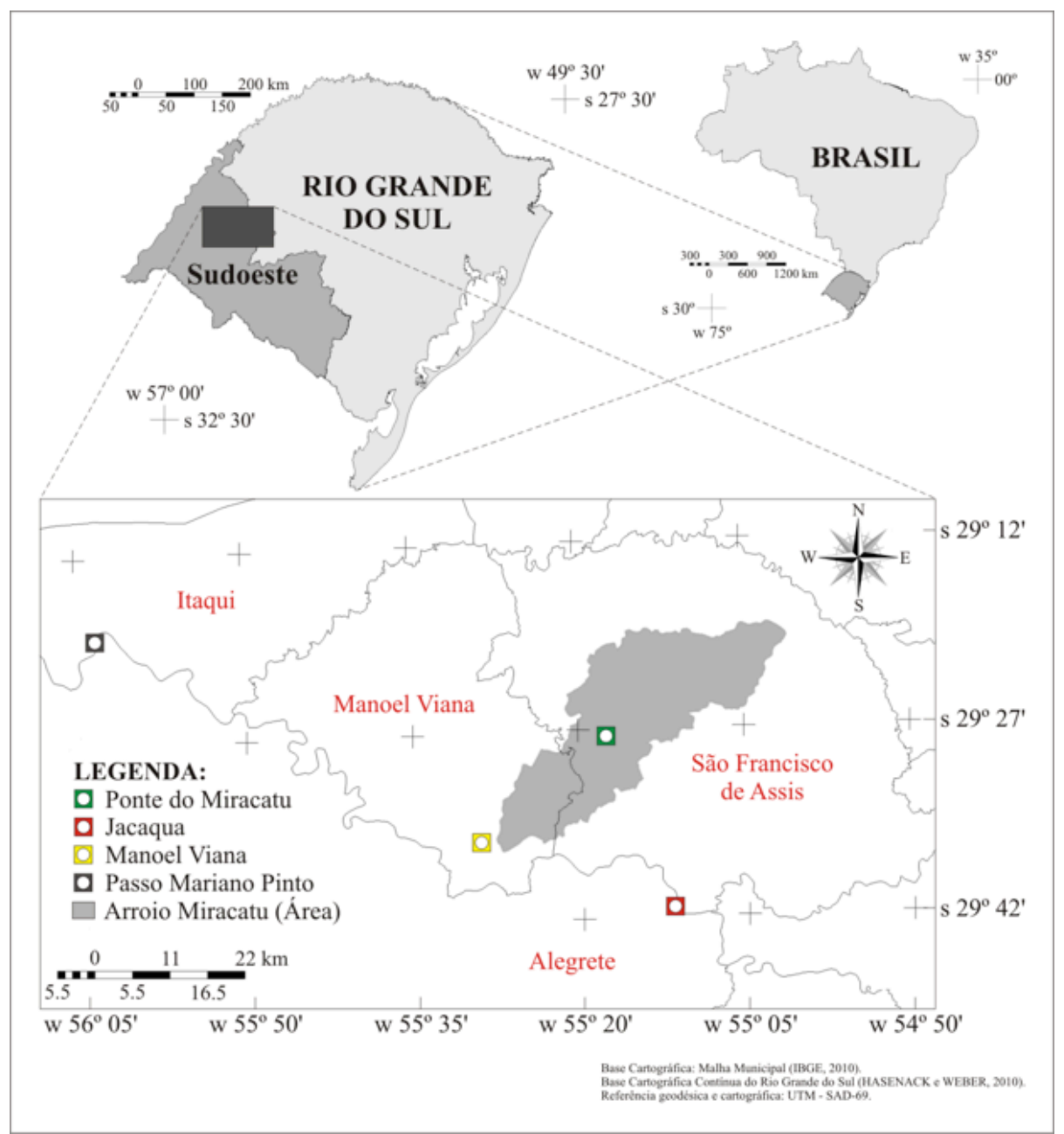

De posse dos dados de cada uma das estações pluviométricas apresentadas, executou-se o preenchimento das falhas mensais com base no método de regressão linear simples (BERTONI e TUCCI, 2009; LANNA, 2009), regressão essa obtida a partir da equação resultante dos meses correspondentes entre as séries históricas. Os coeficientes de determinação $\left(R^{2}\right)$ variaram de 0,65 a 0,90 (Tabela 1). Embora a recomendação para esse procedi- mento indique a necessidade de $R^{2} \geq 0,70$, a consistência da série pluviométrica mensal, após o preenchimento, foi testada pelo método da Dupla Massa (BERTONI e TUCCI, 2009), que apontou para um padrão sem inconsistência, indicando homogeneidade entre os dados $\left(R^{2}>0,99\right)$. 
Tabela 1 - Dados de preenchimento de falhas mensais para a estação pluviométrica "Ponte do Miracatu", São Francisco de Assis/RS.

\begin{tabular}{c|c|c|c|c}
\hline Falha & Estação substituta & $\begin{array}{c}\text { Número de } \\
\text { meses } \\
\text { associados }\end{array}$ & Equação & $\begin{array}{c}\text { Coeficiente de } \\
\text { determinação } \\
\left(\mathbf{R}^{2}\right)\end{array}$ \\
\hline Dezembro/1970 & Passo Mariano Pinto & 42 & $\mathrm{y}=0,938 \mathrm{x}+25,01$ & 0,77 \\
\hline Setembro/2007 & Jacaquá & 12 & $\mathrm{y}=0,918 \mathrm{x}+14,38$ & 0,71 \\
\hline Outubro/2007 & Jacaquá & 13 & $\mathrm{y}=0,755 \mathrm{x}+44,69$ & 0,78 \\
\hline Novembro/2007 & Jacaquá & 12 & $\mathrm{y}=0,876 \mathrm{x}+12,67$ & 0,89 \\
\hline Setembro/2009 & Jacaquá & 12 & $\mathrm{y}=0,918 \mathrm{x}+14,38$ & 0,71 \\
\hline Dezembro/2009 & Jacaquá & 13 & $\mathrm{y}=0,749 \mathrm{x}+20,36$ & 0,90 \\
\hline Janeiro/2010 & Manoel Viana & 36 & $\mathrm{y}=0,577 \mathrm{x}+46,32$ & 0,70 \\
\hline Fevereiro/2010 & Passo Mariano Pinto & 41 & $\mathrm{y}=0,693 \mathrm{x}+40,43$ & 0,65 \\
\hline Abril/2010 & Jacaquá & 13 & $\mathrm{y}=0,670 \mathrm{x}+36,69$ & 0,84 \\
\hline Agosto/2010 & Jacaquá & 13 & $\mathrm{y}=1,32 \mathrm{x}+8,924$ & 0,74
\end{tabular}

Fonte: ANA (1970-2013).

Após preenchimento, a série histórica passou por tratamento estatístico, sobretudo no que se refere às medidas de tendência central, de variabilidade (ou dispersão), de frequência, de regressão e de correlação, cujas orientações gerais podem ser obtidas em Gerardi e Silva (1981) e a aplicação em dados pluviométricos pode ser encontrada adicionalmente em Zavattini e Boin (2013). Além disso, todas as análises estatísticas, bem como as expressões gráficas apresentadas neste trabalho, foram realizadas com auxílio da planilha eletrônica LibreOfficeCalc@ versão 4.2.1.1 disponibilizada por The Document Foundation².

A definição dos anos e dos meses-padrão seguiu a metodologia empregada por Monteiro (1976), a qual classifica a precipitação qualitativamente, com base nos desvios anuais/mensais (anomalias, conforme expressão usada pelo autor) em relação à média. Para uniformizar os dados, empregou-se o coeficiente de variação. Julgou-se mais adequado, entretanto, calcular o coeficiente de variação anual de modo similar àquele mensal (BARRIOS e HERNANDES, 1992), salvo as diferenças temporais. Isso se justifica, pois a soma dos coeficientes mensais para a classificação dos anos-padrão não parece uma medida que reflita, ao menos anualmente, a abundância ou a redução dos totais pluviométricos. Dessa forma, os resultados encontrados são expressos em porcentagem (\%) e discriminados da seguinte maneira: $\geq-30$ seco, -30 a -15 tendente a seco, -15 a 15 normal, 15 a 30 tendente a chuvoso e $\geq 30$ chuvoso (MONTEIRO, 1976; BARRIOS e HERNANDES, 1992).

${ }^{2}$ Copyright@ 2000-2014 LibreOffice The Document Foundation.

\section{RESULTADOS E DISCUSSÕES}

Os resultados das análises de estatística descritiva indicam que, embora a precipitação média anual atinja $1.655,7 \pm 427,0 \mathrm{~mm}$ - mediana de $1.601,0 \mathrm{~mm}$ - distribuídos em cerca de $73 \pm 17$ dias com chuva ${ }^{3}$, há grande variabilidade interanual, tanto na pluviosidade como na quantidade de dias chuvosos, cuja expressão é dada pelo alto desvio-padrão quantificado. 0 desvio-padrão obtido apresenta correspondência com aquele encontrado por Nery (2005) para boa parte do sudoeste gaúcho $( \pm 350$ a $450 \mathrm{~mm})$. Além disso, esses resultados estão de acordo com as informações já apresentadas por outros autores (MACHADO, 1950; SARTORI, 1993a; ROSSATO, 2012) para essa porção do território, onde os acumulados médios se concentraram na faixa de 1.300 a $1.800 \mathrm{~mm}$, precipitados entre 70 a 90 dias com chuva e condicionado a "[...] notáveis desvios pluviométricos anuais" (NIMER, 1989, p.260).

Chama-se a atenção para o fato de que o volume de chuvas anuais é elevado, superior inclusive ao de outras regiões do Rio Grande do Sul, tal como o litoral (MACHADO, 1950; NIMER, 1989; SARTORI, 1993a). Fontana e Almeida (2002) descrevem, no entanto, que, no sudoeste, o número de dias com chuva corresponde aos menores observados no estado. Isso corrobora para que as chuvas nessa mesorregião sejam mais intensas (TEIXEIRA, 2010), uma vez que o acumulado pluviométrico anual ocorre em menor número de dias com

${ }^{3}$ Considerou-se dia com chuva aquele com total acumulado $\geq 1 \mathrm{~mm}$ conforme recomendam Petersen et al. (2014) e da mesma forma como empregado por diversos autores (ex. NERY, 1996; ROSSATO, 2012). Dias com precipitação < mm, são tratados como "vestígio de chuva" (PETERSEN et al. (2014) e foram contabilizados nos volumes totais anuais e mensais. 
chuva, influenciando positivamente na erosividade da precipitação. Azevedo e Kaminski (1995) já alertavam para o fato de que as chuvas mal distribuídas correspondem a um dos fatores primordiais para a erosão dos solos e, consequentemente, para o surgimento de ravinas, de voçorocas e de novos núcleos de arenização.

A precipitação, todavia, varia de um ano para outro e isso decorre do fato de que os próprios sistemas atmosféricos não se comportam de maneira idêntica ao longo do tempo (NERY, 1996). Dessa forma, torna-se importante observar como os totais anuais se distribuem no decurso da série histórica. Na Figura 2 é apresentada a distribuição dos totais pluviométricos anuais e sua variação em torno do valor da média anual, bem como, os limites superior e inferior do desvio-padrão. Assim sendo, aduz que os anos de 1982 (2.399,3 mm), 1984 (2.489,3 mm), $1986(2.477,8 \mathrm{~mm}), 1987(2.209,5 \mathrm{~mm}) 1990(2.294,2$ $\mathrm{mm}), 1998(2.395,6 \mathrm{~mm}), 2002(2.623,3 \mathrm{~mm})$ e 2003 $(2.123,9 \mathrm{~mm})$, por superarem a linha superior, podem ser caracterizados como anos excepcionalmente chuvosos. Em oposição, os anos de 1970 (1.148,2 mm), 1971 (1.125,5 mm), 1974 (1.068,9 mm), 1977 (990,8 mm), 1978 (1.008,6 mm), 1991 (1.091,2 mm) e $2004(984,5 \mathrm{~mm})$, por estarem abaixo da linha inferior, podem ser considerados como anos com menores índices pluviométricos.

Figura 2 - Total anual de chuva, média e desvios-padrão para a estação pluviométrica "Ponte do Miracatu", São Francisco de Assis/RS.

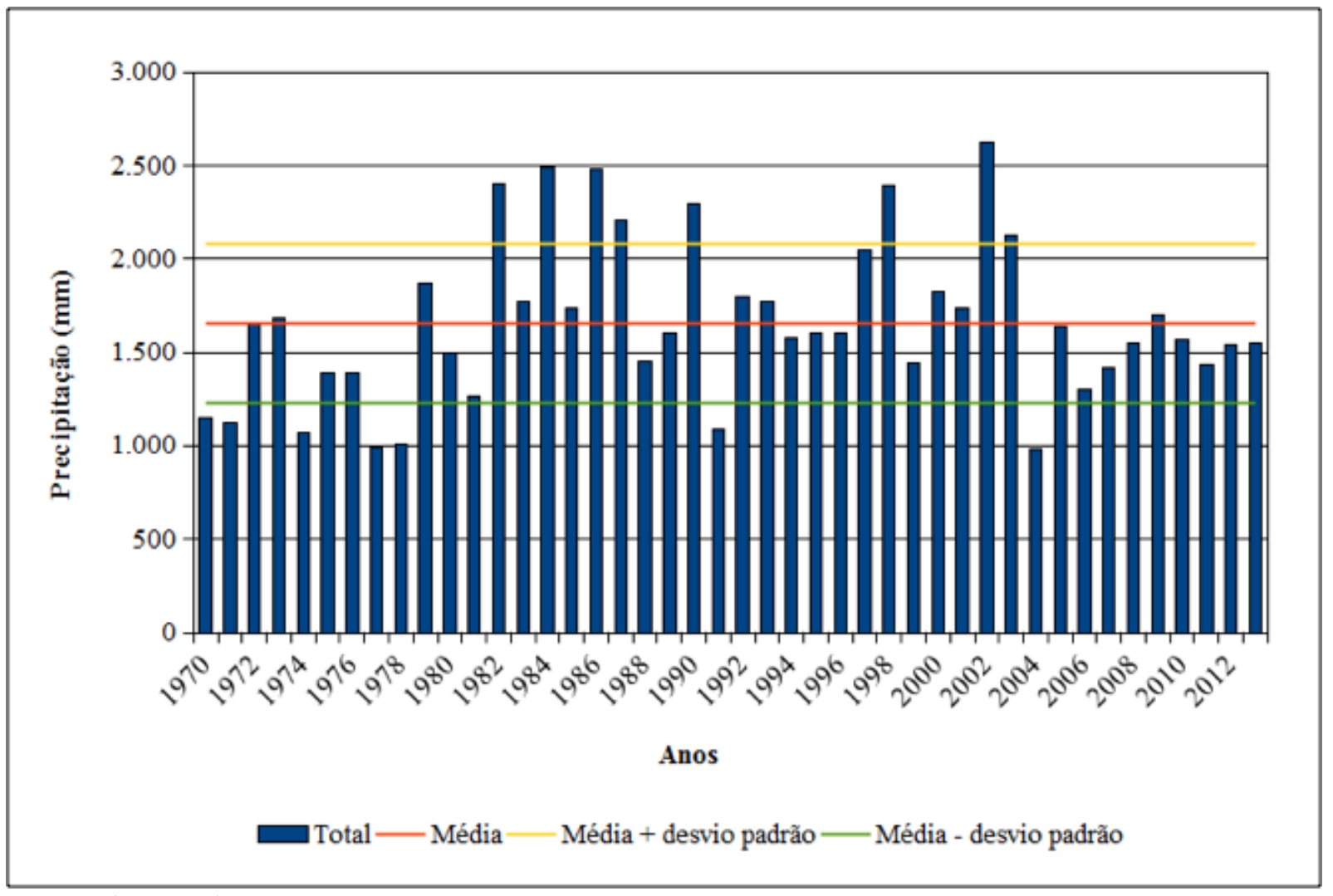

Fonte: ANA (1970-2013). 
Quanto aos dias com chuva (Figura 3), a relação é expressa por anos com mais/menos dias chuvosos na série histórica. De acordo com a Figura 3, os anos com maior total de dias com chuva foram: 1982 (96 dias), 1984 (100 dias), 1986 (105 dias), 1987 (108 dias), 1992 (95 dias) e 2002 (102 dias), ao passo que os anos de 1970 (46 dias), 1971 (46 dias), 1974 (45 dias), 1975 (55 dias), 1976 (54 dias), 1977 (53 dias) e 1978 (48 dias) totalizaram menor quantidade de dias com chuva. Machado(1950), base- ado em dados coletados na primeira metade do século $\mathrm{XX}$, descreve um valor mínimo de 47 dias com chuva em Santiago/RS (distante cerca de $50 \mathrm{~km}$ da área de estudo e localizada no topo do planalto, a 409 metros de altitude) no ano de 1933. Essa informação contribui no sentido de validar os dados aqui apresentados e indicar que a ocorrência de anos com reduzido número de dias com chuva é algo que pode ocorrer com certa frequência na BHAM.

Figura 3 - Número de dias com chuva, média e desvios-padrão para a estação pluviométrica "Ponte do Miracatu", São Francisco de Assis/RS.

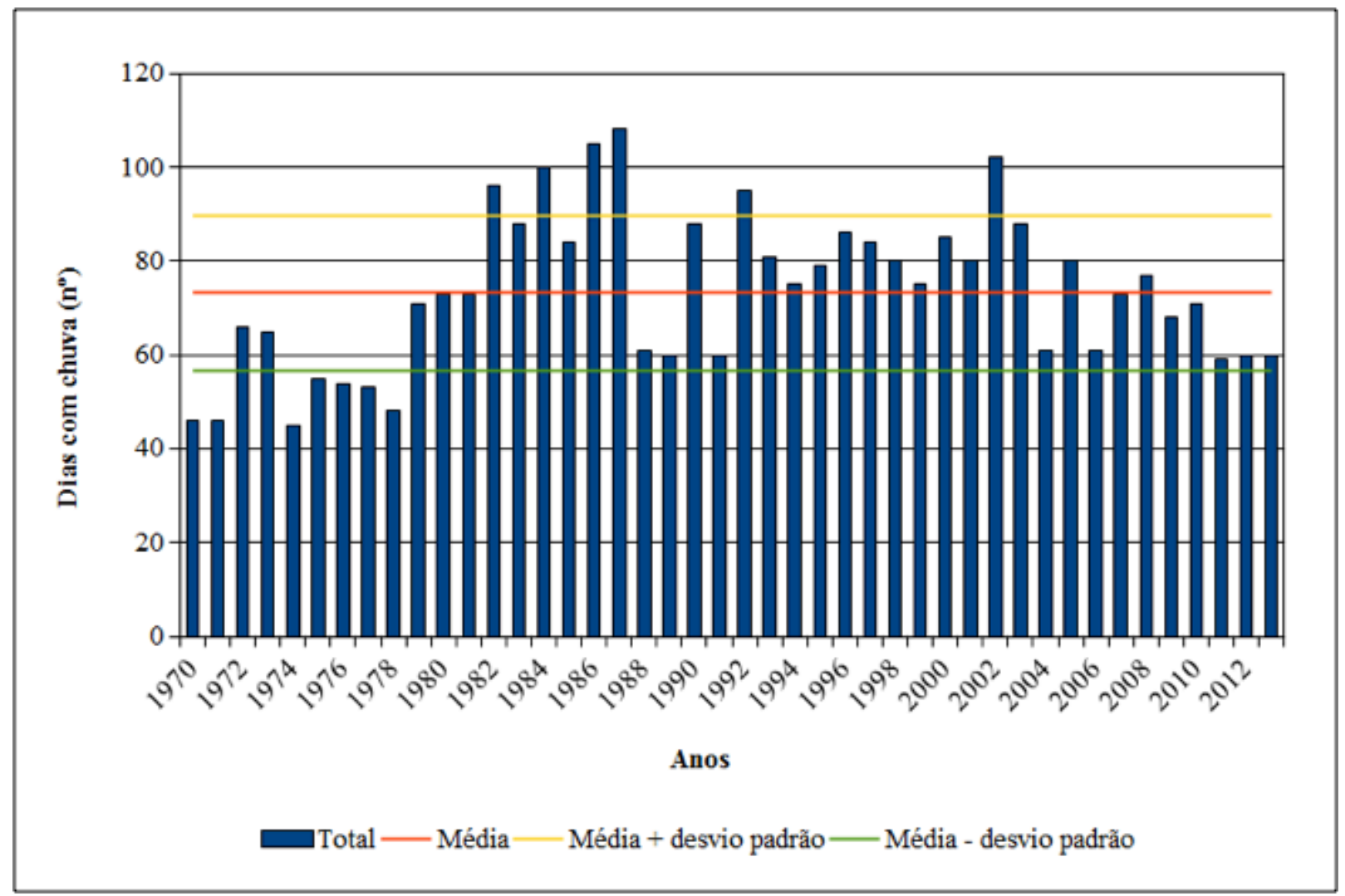

Fonte: ANA (1970-2013). 
Com o intuito de tentar melhorar a análise das chuvas anuais, buscou-se discriminar os volumes totais a partir de uma classificação que representasse as características das precipitações. Machado (1950), em seu clássico trabalho sobre o clima do Rio Grande do Sul, apresentou uma das primeiras tentativas de classificação das chuvas no estado, considerando a premissa de que "Os totais mensais da precipitação em 6 meses, no mínimo, devem ser bastante superiores (ano chuvoso), ou muito inferiores (ano sêco [sic]) aos respectivos normais" (MACHADO, 1950, p.26). Serra (1969) também tratou dos anos secos e chuvosos no estado, com destaque à circulação atmosférica.

Wollmann e Sartori (2009), considerando o estado do Rio Grande do Sul, utilizaram a nomenclatura de anos menos chuvosos ao invés de secos, uma vez que termo "seco", segundo eles, seria mais bem adequado a climas áridos e semiáridos. Todavia, qualificar os anos-padrão como "mais ou menos chuvosos" não oferece uma medida qualitativa que exprima a visão ímpar entre os anos- -padrão seco e chuvoso. Devido a isso, optou-se por utilizar o termo "seco", mantendo a terminologia empregada por Monteiro (1976), mas com a ressalva de que essa qualidade advém da média anual de chuvas na BHAM.

Assim, examinando a série histórica, pode-se chegar à seguinte discriminação (Figura 4): sete anos foram classificados como secos $(1970,1971,1974,1977,1978$, 1991 e 2004), quatro como tendentes a secos $(1975,1976$, 1981 e 2006), dois como tendentes a chuvosos (1997 e 2003) e sete como chuvosos (1982, 1984, 1986, 1987, 1990, 1998 e 2002). Como pode ser visto, houve predominância de anos-padrão normais, que foram registrados em 24 anos da série de dados $(1972,1973,1979$, 1980, 1983, 1985, 1988, 1989, 1992-1996, 1999-2001, 2005 e 2007-2013). Chama-se a atenção para o fato de que é clara a sucessão de anos-padrão secos/tendentes a secos, principalmente na década de 1970 e pós-2003, do mesmo modo que anos-padrão chuvosos/tendentes a chuvosos se concentram no período entre 1982-2003, atestando vínculos com mecanismos de teleconexões.

Figura 4 - Definição de anos-padrão para a estação pluviométrica "Ponte do Miracatu", São Francisco de Assis/RS.

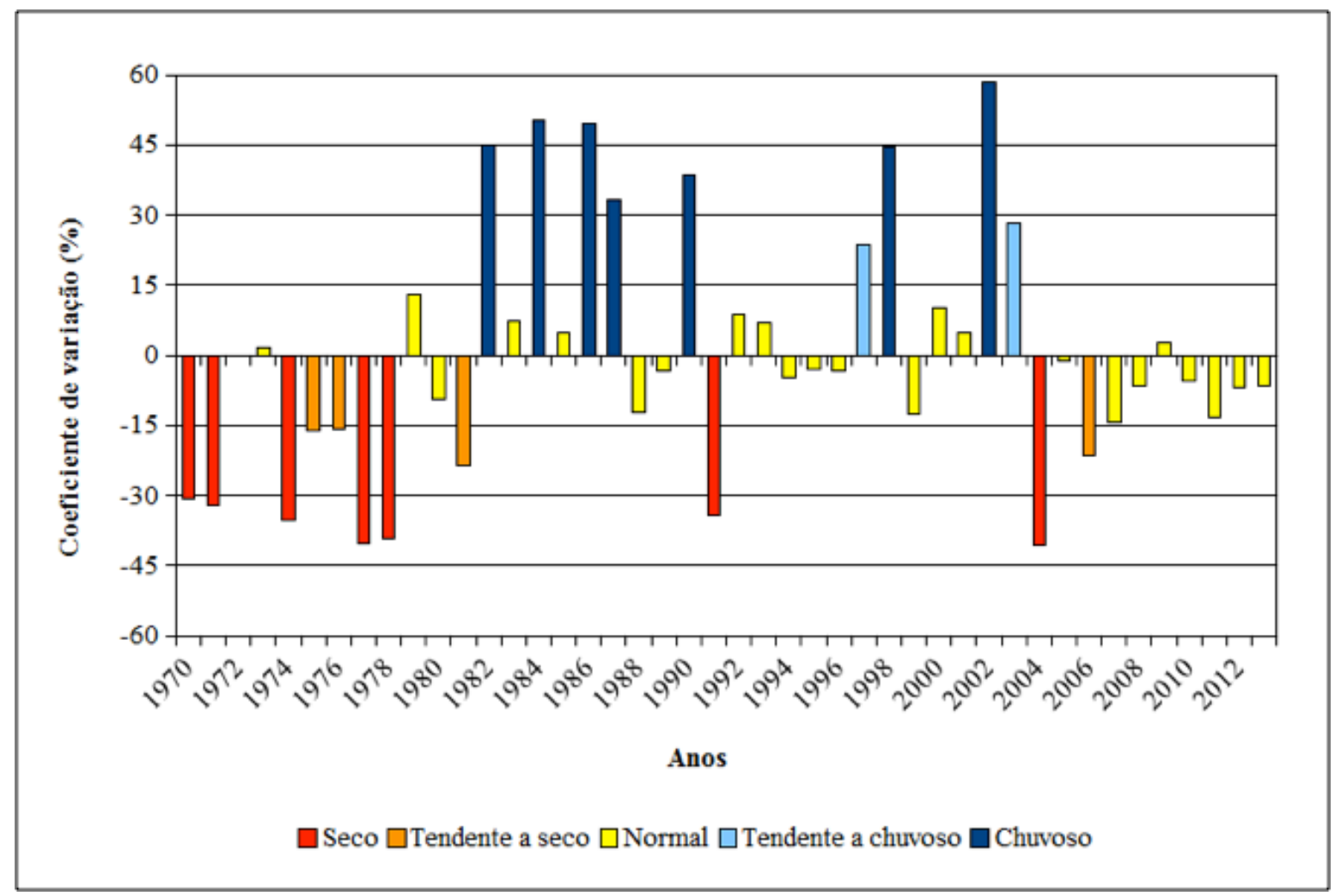

Fonte: ANA (1970-2013) 
Quando se analisa a pluviosidade e o número de dias com chuva anual em conjunto, observa-se que há uma tendência de que o aumento dos totais pluviométricos seja acompanhado pelo aumento no número de dias com chuva. Fontana e Almeida (2002) encontraram resultados similares para o estado como um todo. Isso poderia indicar, simplesmente, que a definição dos anos-padrão estaria relacionada, tão somente, ao número de dias chuva, que modulariam a precipitação anual (Figura 5) e, assim, tenderiam a demonstrar um regime pluviométrico homogêneo.

Figura 5 - Relação entre o total anual, dias com chuva e anos-padrão para a estação pluviométrica "Ponte do Miracatu", São Francisco de Assis/RS.

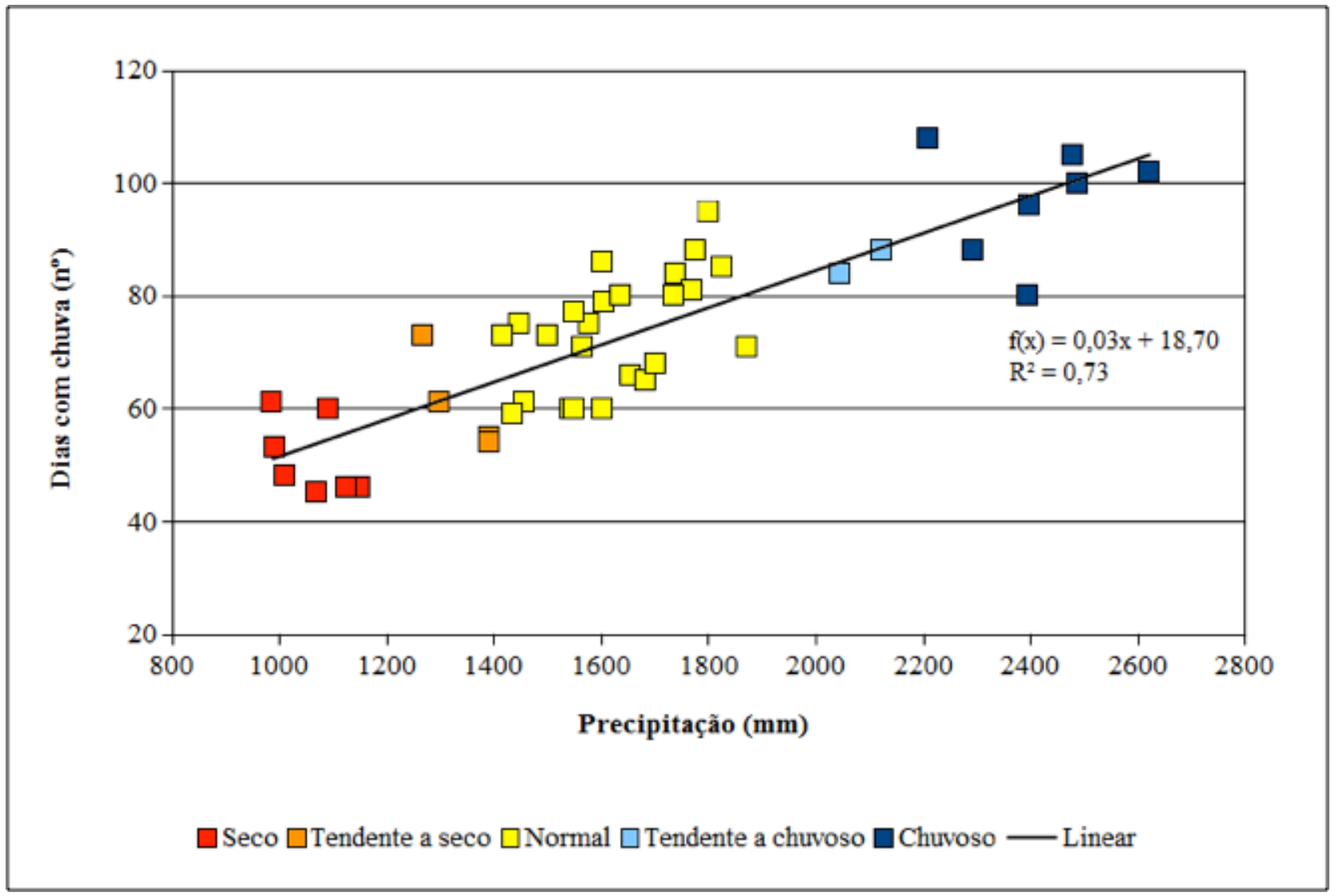

Fonte: ANA (1970-2013).

Para tentar verificar a confiabilidade desses dados foi realizada a correlação linear por meio da inserção da reta de regressão, cujo coeficiente de correlação $(r=0,85)$ demonstra forte tendência positiva, que também é expressa pelo alto coeficiente de determinação $\left(R^{2}=0,73\right)$. Fica claro, porém, que ocorrem resíduos tanto positivos quanto negativos em torno dessa reta (erro padrão de nove dias) e esses adquirem uma importância fundamental que se opõe à afırmação acima exposta. Depreende-se que resíduos negativos se relacionariam aos anos que registraram chuvas mais intensas, visto que o total precipitado ocorreu em menor quantidade de dias com chuva, enquanto que os resíduos positivos expressariam anos com chuvas mais bem distribuídas.

Uma informação importante, no que se refere às características da precipitação em clima subtropical, está na afirmação de que essa ocorre bem distribuída ao longo do ano (MONTEIRO, 1968; NIMER, 1989; MENDONÇA e DANNI-OLIVEIRA, 2007; GRIMM, 2009). Para o estado do Rio Grande do Sul, essa alegação também 
pode ser observada, tanto na distribuição equitativa mensal, como na estacional (MORENO, 1961; DIAZ et al., 1998; FONTANA e ALMEIDA, 2002), não existindo, portanto, nenhum mês seco (MONTEIRO, 1968; SARTORI, 1993b). Ocorre, no entanto, que essas assertivas estão baseadas na descrição das chuvas com base nas médias, de tal forma que "[...] não devem ser interpretados como uma realidade de cada ano" (NIMER, 1989, p.220).

De fato, os autores supracitados buscaram, com essa descrição, demonstrar que a precipitação não apresenta sazonalidade na região (MORENO, 1961; NERY, 1996; DIAZ et al., 1998) e, portanto, inexiste uma estação seca ou chuvosa bem definida (MONTEIRO, 1968; NIMER, 1989; SARTORI, 1993b; TEIXEIRA, 2010). Todavia, os mecanismos de gênese da chuva, devido à migração norte-sul, tendem a ser sazonais ao longo do ano (AYOADE, 2010; TEIXEIRA, 2010). Mesmo assim, é conveniente evitar esse tipo de generalização, pois dão a falsa ideia de uniformidade na distribuição das chuvas ao longo do ano, com "[...] fenômenos extremos, de grande importância geográfica, que ficam completamente desaparecidos nos valôres [sic] 'médios' dos dados [...]" (MONTEIRO, 1968, p.116).

Vianello e Alves (2012, p.367) enfatizam, por exemplo, que a explicação do comportamento normal de uma variável meteorológica, tal como a precipitação, deve antes se ater ao seguinte: "[...] que as irregularidades dos fenômenos são as regras gerais e não as exceções" ou, então, conforme Zavattini e Boin (2013, p.31): "[...] distinguir o que lhes é habitual (ocorrência mais frequente) do que thes é excepcional (ocorrências esporádicas)".

Por consequência, tomando-se como regra as médias mensais de chuvas na BHAM, obter-se-ia um regime pluviométrico tal como apresentado, homogêneo, uma vez que, com exceção do mês de agosto, todos os demais apresentaram valores acima de $100 \mathrm{~mm}$. Observando somente pelo viés da média, pouca informação é obtida, uma vez que se desconhece o regime das chuvas e como elas se distribuem ao longo do ano (LEOPOLD et al., 1964).

Como visto para a precipitação anual, as chuvas médias mensais (em torno de 138,0 $\pm 20,5 \mathrm{~mm} / \mathrm{mês}$ ) também apresentaram grande variabilidade, com variáveis que podem ser expressas não apenas por seus volumes, mas pelos desvios-padrão que vão de 53,7 $\mathrm{mm}$ em agosto até $121,1 \mathrm{~mm}$ em abril. Para se exemplificar, Nery (1996) observou que os maiores desvios-padrão ocorreram no oeste do Rio Grande do Sul, o que se reflete nas informações prestadas por Hasenack (1981), que demonstrou a significativa variabilidade pluviométrica mensal no sudoeste do estado, sobretudo nos meses de transição entre inverno e verão.

É possível notar que, apreciando apenas os valores de precipitação máxima e mínima mensal, há elevada variabilidade. Totais máximos mensais entre 300 até perto de $500 \mathrm{~mm}$ ocorreram em todos os meses, exceto em agosto, onde o maior valor foi de $235,0 \mathrm{~mm}$. Em compensação, os mínimos absolutos ficaram sempre abaixo dos $20 \mathrm{~mm}$, salvo junho $(22,8 \mathrm{~mm})$. Esses valores máximos e mínimos demonstram elevada amplitude pluviométrica mensal. Nesse sentido, parece claro que o mês de agosto foge da regra, ainda mais quando considerado o menor desvio-padrão mensal observado. Isso deixa evidente que esse mês de inverno no hemisfério sul apresenta tendência de menores totais pluviométricos quando comparados aos demais.

Em oposição, os meses de abril (média de 180,4 mm e mediana de 140,8 $\mathrm{mm}$ ) e outubro (média 169,1 mm e mediana de 150,4 mm), mais chuvosos, apresentam desvios-padrão mensais altos, de 121,1 mm e 116,6 mm, respectivamente, o que permite afirmar que se trata de meses com tendência para serem chuvosos, mas que essa relação é extremamente variável de um ano para outro. Destaca-se, ainda, o mês de novembro, cujo desvio-padrão atinge $117,0 \mathrm{~mm}$. Esse valor pode, no entanto, ter sido influenciado pelo evento extremo absoluto de chuva mensal, que quantificou 512,6 mm em 2009.

Observa-se, contudo, em linhas gerais, que esses aspectos demonstram que qualquer mês pode apresentar tanto volumes expressivos de chuva, como também totais pluviométricos pouco representativos. Isso atesta a inexistência de sazonalidade sob a forma de uma estação seca ou de uma estação chuvosa bem definida, o que não significa que inexistam meses com maior concentração ou com maior escassez de chuva. Assim, com a finalidade de investigar esses aspectos, elaborou-se a Figura 6, a qual apresenta os volumes mensais de precipitação de toda a série histórica de 44 anos, totalizando 528 meses, a exemplo do que foi apresentado por Verdum (1997). A distribuição das chuvas em cada mês, como se supunha, é alta, mas parece existir, sim, um padrão para o regime pluviométrico. 
Figura 6 - Distribuição dos totais pluviométricos mensais para o posto "Ponte do Miracatu", São Francisco de Assis/RS.

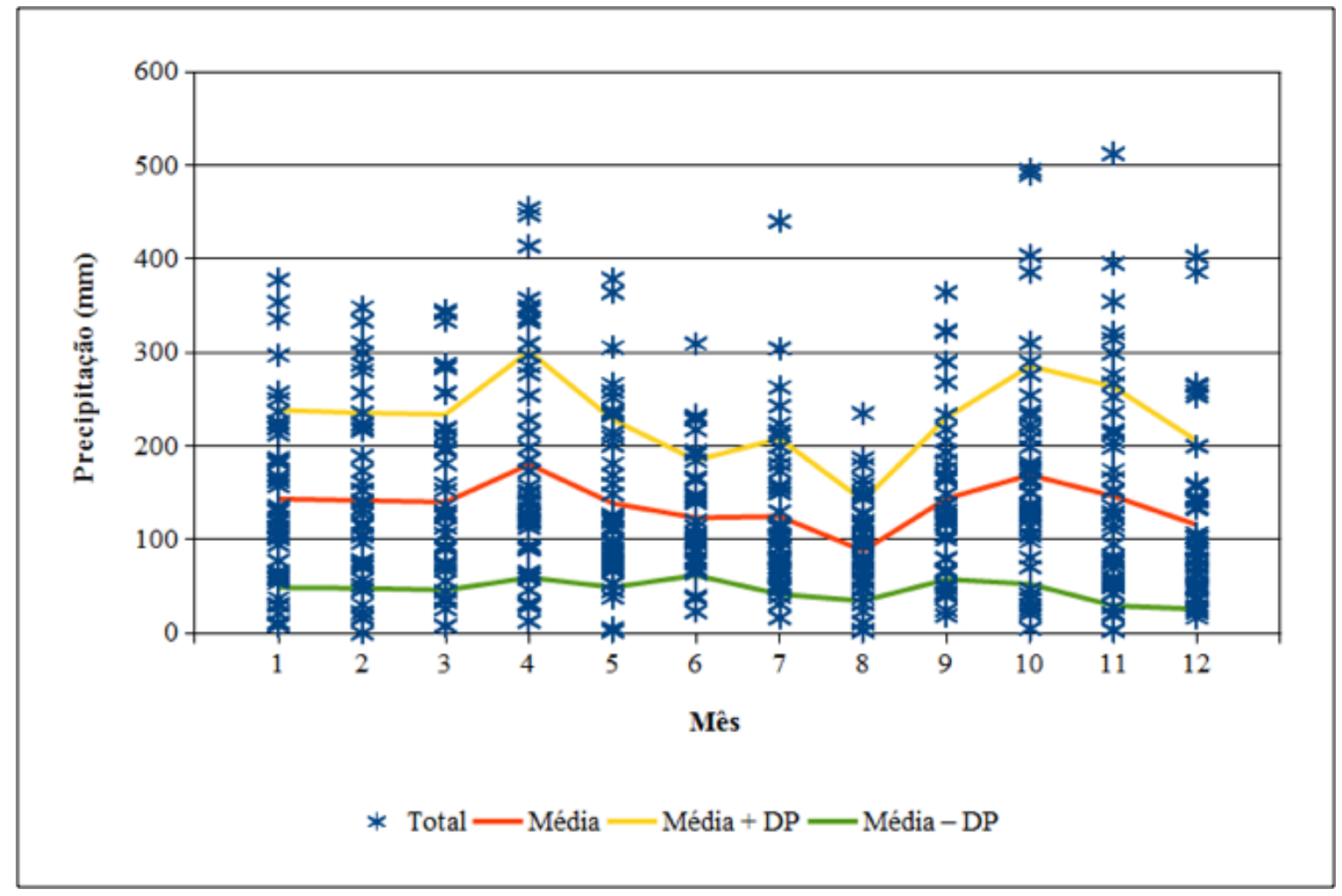

Fonte: ANA (1970-2013).

Verdum (1997), utilizando dados da mesma estação pluviométrica (período de 1971-1992), discrimina que o regime pluviométrico pode ser expresso em dois máximos (abril e setembro) separados, igualmente, por dois mínimos (agosto e dezembro). 0 autor supracitado salienta, ainda, que o mês mais chuvoso foi abril e que, durante a primavera, o mês de setembro destacava-se no volume precipitado. Isso é algo interessante, pois os dados aqui apresentados, por perfazerem uma série mais longa, apresentam sutis diferenças, conforme será descrito a seguir.

A posição dos mínimos em agosto e dezembro ainda parece clara, mas as chuvas concentradas outrora em setembro parecem ter migrado para outubro, bem como, intensificadas. Nesse mês foram registrados, por exemplo, três casos excepcionais que quantificaram 495,3 $\mathrm{mm}, 490,6 \mathrm{~mm}$ e $386,3 \mathrm{~mm}$, respectivamente nos anos de 1997, 2002 e 2009. Nota-se, no entanto, que o mês de novembro também apresenta elevada pluviosidade e, diferentemente do mês anterior, seus valores estão distribuídos de modo mais uniforme, com exceção do evento de extremo absoluto descrito acima. Sanches (2013), trabalhando com dados de Alegrete/RS, percebeu, justamente, a existência de tendência positiva para as chuvas no mês de novembro, com destaque para aquelas acima de $80 \mathrm{~mm}$. Esses resultados devem estar vinculados à passagem de frentes frias que interagem com os processos de convecção tropical (TEIXEIRA, 2010), que, segundo Cavalcanti e Kousky (2009), é máxima justamente nos meses de outubro e novembro.

Julho e dezembro, por sua vez, embora apresentem picos máximos de precipitação mensal, em torno de 400 $\mathrm{mm}$, tendem a se vincular, normalmente, com volumes muito menores. Chama-se atenção, porém, para o fato de que, nos anos de 2003 (402,4 mm) e 2012 (385,9 mm), o mês de dezembro recebeu chuvas extremas, muito acima daquelas descritas por Verdum (1997). Essa característica indica que, tanto a precipitação média mensal, como os volumes totais de chuva mensais apresentam um padrão bimodal (dois picos) de chuva como mostrado acima. Esse padrão é comum para parte do Rio Grande do Sul, conforme apontado por Grimm (2009). 
Fundamentado no trabalho de Sartori (1993a), nota-se que a posição dos máximos e dos mínimos de chuva mensal na área de estudo preserva características de duas regiões climáticas do Rio Grande do Sul: com o baixo vale do Uruguai, onde os máximos ocorrem em março/abril e os mínimos em julho/agosto e com a região da campanha, cujos máximos se concentram em setembro/outubro e os mínimos em dezembro. Isso confere à BHAM uma possível área de transição e, por assim ser tratada, a ocorrência dos valores extremos mensais pode ser resultado dessa característica.

Outra interrogação que necessita ser esclarecida está relacionada com o número de dias com chuva mensal. Para isso, confeccionou-se a Tabela 2, a qual apresenta os valores máximos, mínimos, médios e de desvio-padrão. Sumariamente, os valores máximos absolutos de dias com chuva mensal variaram de 11 (março, agosto, setembro e dezembro) até 17 (outubro), enquanto que os valores mínimos absolutos estiveram entre nenhum dia (fevereiro) a 2 (março, junho e setembro). Em termos médios, nota-se que os valores não apresentam grande variação, uma vez que se encontram entre cinco e sete dias com chuva mensal, com desvios-padrão entre três e quatro dias, exceto junho e dezembro, com dois dias.

Esses valores são condizentes com aqueles apresentados por Rossato (2012) para a região sudoeste do Rio Grande do Sul e tonificam a hipótese de que as chuvas mensais são distribuídas em poucos dias. Teixeira (2010) apontou o setor oeste do Rio Grande do Sul como um núcleo de chuvas intensas, que destoa não somente do restante da região sul, mas que também supera os dados examinados de todo o sudeste brasileiro. Esse aspecto indica, portanto, uma possível natureza torrencial das chuvas, que constituiriam uma importante força motriz para os processos geomorfológicos identificados na área de estudo.

Tabela 2 - Número de dias com chuva máximos e mínimos absolutos, média e desvio-padrão para a estação pluviométrica "Ponte do Miracatu", São Francisco de Assis/RS.

\begin{tabular}{|c|c|c|c|c|}
\hline Mês & $\mathbf{x}$ & $\mathbf{S}$ & $\mathbf{M x}$ & $\mathbf{M i}$ \\
\hline Janeiro & 7 & 3 & 13 & 1 \\
\hline Fevereiro & 7 & 3 & 14 & 0 \\
\hline Março & 6 & 3 & 11 & 2 \\
\hline Abril & 6 & 3 & 13 & 1 \\
\hline Maio & 5 & 3 & 12 & 1 \\
\hline Junho & 6 & 2 & 13 & 2 \\
\hline Julho & 6 & 3 & 15 & 1 \\
\hline Agosto & 6 & 3 & 11 & 1 \\
\hline Setembro & 7 & 3 & 11 & 2 \\
\hline Outubro & 7 & 4 & 17 & 1 \\
\hline Novembro & 6 & 3 & 13 & 1 \\
\hline Dezembro & 6 & 2 & 11 & 1 \\
\hline
\end{tabular}

Legenda: x: média, s: desvio-padrão, Mx: máximo e Mi: mínimo.

Fonte: ANA (1970-2013) 
Contudo, aqui se coloca o seguinte questionamento: - Seria a classificação dos anos-padrão uma representação das condições pluviométricas mensais para um determinado ano? Vale recordar que, para a definição dos anos-padrão foi utilizada a relação entre o total precipitado naquele ano com a média anual. Embora essa classificação seja fundamental para caracterizar o regime das chuvas anuais, acaba mascarando a sua distribuição mensal, pois dá a falsa ideia de que determinadas condições prevaleceram ao longo de todos os meses. Machado (1950, p.26) já chamou a atenção para esse fato ao frisar que, "[...] em verdade, não houve, como veremos, ano algum totalmente sêco [sic], chuvoso ou normal, no sentido rigoroso da expressão [...] o ano de 1941, apesar de se destacar como excepcionalmente chuvoso, apresentou meses secos e normais [...]". Para representar essa característica, aplicou-se a mesma metodologia de Monteiro (1976), com as contribuições de Barrios e Hernandes (1992). Agora, porém, o foco foi a definição dos meses-padrão e a sua frequência acumulada por classe ao longo dos anos, que é apresentada na Figura 7.

Figura 7 - Frequência anual acumulada dos meses-padrão para a estação pluviométrica "Ponte do Miracatu", São Francisco de Assis/RS.

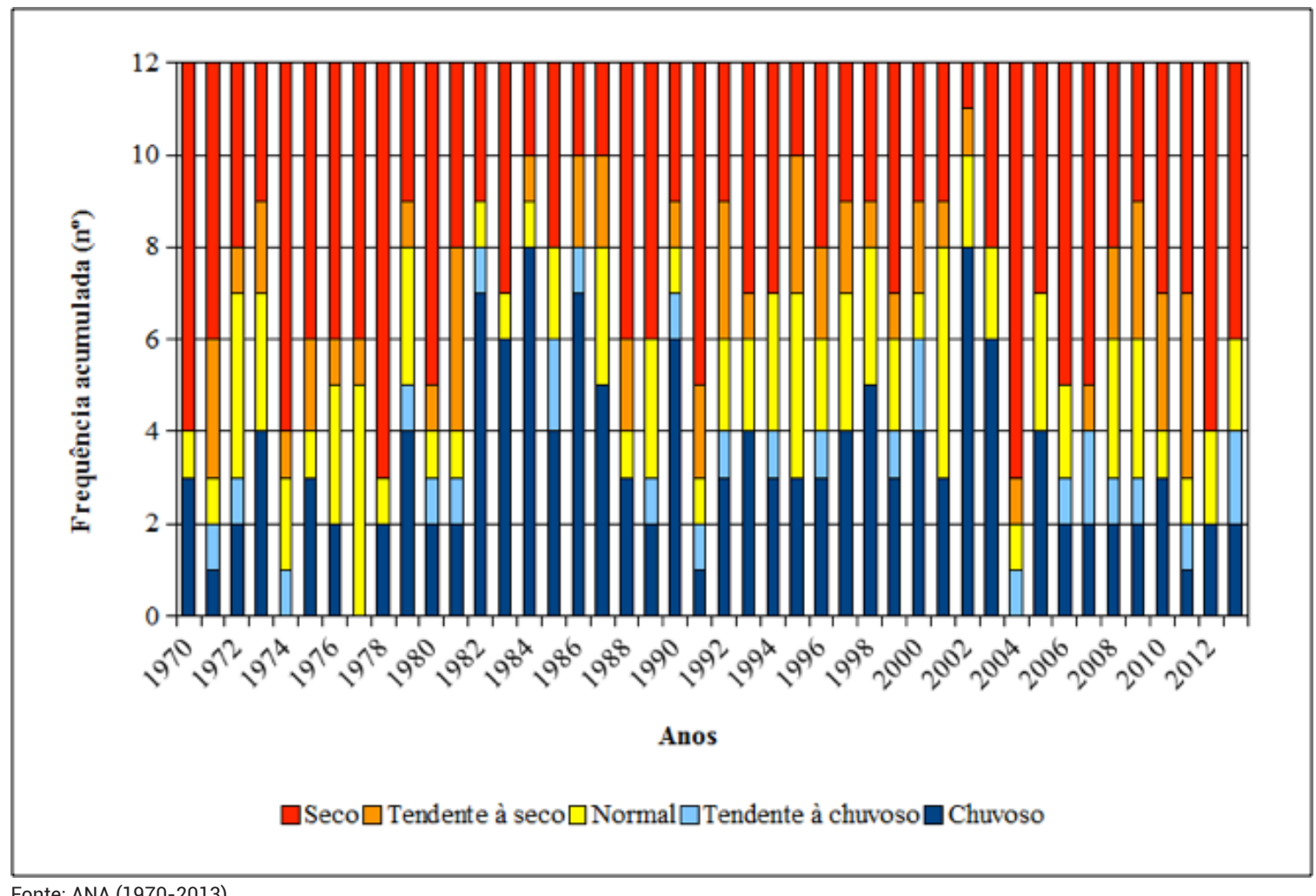

Fonte: ANA (1970-2013). 
Como pode ser visualizado, mesmo os anos-padrão secos ou tendentes a secos podem apresentar meses chuvosos ou tendentes a chuvosos, cuja única exceção é 1977. Além disso, nos anos de 1974 e 2004 ocorreu apenas um mês tendente a chuvoso, ao passo que nos demais anos classificados como secos houve concentração nas categorias normais, tendentes a secos ou secos, com predominância do último. Isso é um indicador de que esses três anos parecem ter apresentado, além de chuvas reduzidas, volumes mensais pouco expressivos ao longo de todo o ano e que podem ter contribuído para um período de relativa estabilidade geomorfológica.

Por outro lado, os anos tidos como chuvosos e tendentes a chuvosos, sem exceções, registraram, da mesma forma, meses secos ou tendentes a secos. Inclusive os anos de 1987 e 1998, bem como, o ano de 1997 computaram, nesta ordem, quatro e cinco meses secos ou tendentes a secos. Além disso, atenta-se para os anos de 1978 e 2004, para os quais foram registrados extremos de nove meses secos e os anos de 1982 e 2002 com, respectivamente, sete e oito meses chuvosos, o que torna evidente que, tanto anualmente, como mensalmente, a dinâmica do meio na BHAM seria caracterizada por momentos de estabilidade, enquanto, em outros, o trabalho geomorfológico e a esculturação nas vertentes e nos fundos de vale seriam altamente ativos.

É importante observar ainda que diversos anos tratados como normais também quantificaram meses chuvosos ou secos. Machado (1950) cita o caso de Porto Alegre/RS no ano de 1944, atestando que, embora apresentasse características de um ano seco, a pluviosidade total acabou próxima da média devido à contribuição de um elevado volume de chuvas no mês de junho. Na Figura 7 nota-se que, dos 24 anos, inicialmente tratados como normais, 17 deles podem ser considerados como irregulares: 14 por apresentarem prioritariamente meses secos e tendentes a secos $(1980,1988-1989,1992-1993,1996$, 1999, 2007-2013) e três por conterem maior participação de meses chuvosos e tendentes a chuvosos $(1983,1985$ e 2000). Tendo em vista que a maior parte dos anos-padrão recaiu sobre a categoria normal, nota-se, com a discriminação dos meses-padrão, que, mesmo nestes anos, a ocorrência de meses chuvosos e secos pode afetar consideravelmente os processos hidrogeomorfológicos.

É oportuno verificar, também, a frequência mensal dos meses-padrão (Figura 8). Observa-se que todos os meses foram passíveis de se enquadrarem em qualquer uma das classes. 0 importante é que essa distribuição confirma que qualquer mês pode apresentar situações opostas, ou seja, desde meses-padrão secos até chuvosos. Neste ponto, concorda-se com Nimer (1989) quando afirma que os maiores e menores totais pluviométricos podem ocorrer em qualquer época do ano. Todavia, a distribuição, tal como suposta, está longe de ser "[...] quase eqüitativa [sic] ao longo do ano [...]" (NIMER, 1989, p.215).

Entretanto, chama-se a atenção para o fato de que os meses chuvosos e tendentes a chuvosos aparecem com um padrão bimodal, ou seja, com dois picos, um em abril e outro em outubro, o que corrobora a assertiva da discriminação do regime pluviométrico acima abordado. Mesmo assim, contudo, ao considerar os meses secos e tendentes a secos, observa-se um padrão diferenciado, com picos em março, agosto e dezembro, ou seja, trimodal. Isso significa que esses meses têm maior probabilidade de registrarem chuvas reduzidas, sobretudo nas classes de meses-padrão secos e tendentes a secos. Além disso, corrobora o entendimento de se tratar dos meses de agosto e dezembro como tendentes a reduções nos totais pluviométricos.

Atenta-se, ainda, para uma condição peculiar na distribuição dos meses-padrão: a maior parte dos meses (40\%) recebeu a classificação de secos e, secundariamente, como chuvosos $(27 \%)$. Meses normais corresponderam a $17 \%$, enquanto meses tendentes a chuvosos e tendentes a secos atingiram, respectivamente, $5 \%$ e $11 \%$ (Figura 9). 
Figura 8 - Frequência acumulada dos meses-padrão para a estação pluviométrica "Ponte do Miracatu", São Francisco de Assis/RS.

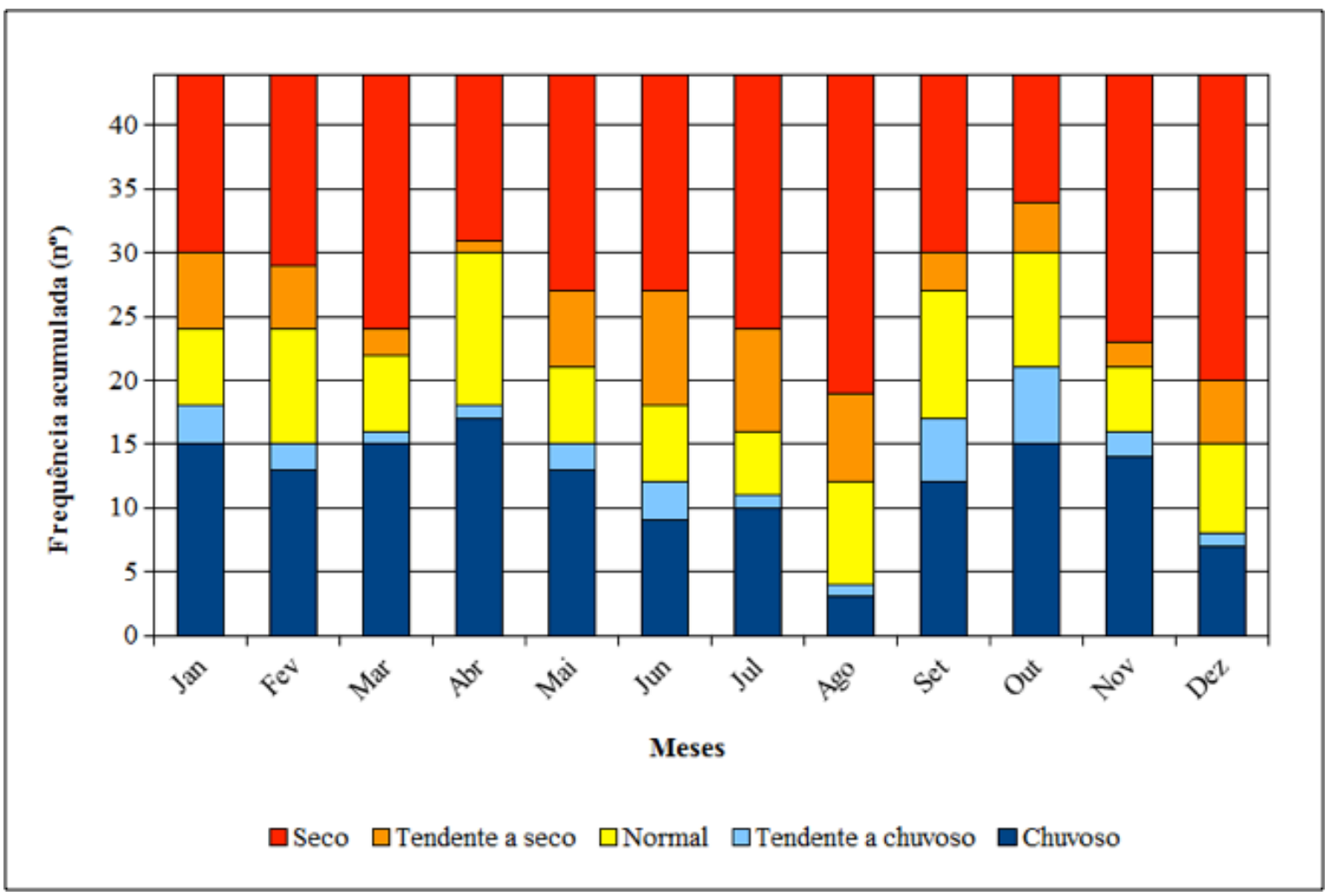

Fonte: ANA (1970-2013).

Scopel et al. (2012) atestam que o nível superficial dos solos da região (Neossolos Quartzarênicosórticos), quando em situação de déficit hídrico, tende a adquirir consistência solta, ainda mais quando há revolvimento do solo para atividades agrícolas ou devido ao pisoteio do gado. Com isso, os meses identificados com menor participação nos totais pluviométricos, quando sucedidos por meses chuvosos, podem ter respondido com intensa atividade erosiva, uma vez que a friabilidade do solo, quando submetido a chuvas intensas, pode ter promovido substancial movimentação de material. Esse é um dado pertinente de como pode haver intensificação nos processos de arenização, quando um mês seco é sucedido por outro chuvoso, algo que parece ser um tanto comum na BHAM.
Esses meses-padrão chuvosos e secos representariam, portanto, uma importância fundamental para os próprios processos de arenização e de transferência de sedimentos na BHAM. Freitas et al. (2009) correlacionaram a dinâmica das chuvas com a florística e a fitossociologia da vegetação em duas áreas distintas: uma sob arenização e outra sem a presença desse processo, ambas com regime de pastejo contínuo. Períodos com chuva reduzida (secos) induziram ao ressecamento do solo, facilitando a desagregação da cobertura pedológica pelo pisoteio do gado. Adicionalmente, a pressão exercida pela redução das chuvas resultou no aumento das áreas de solo exposto, devido ao ressecamento da vegetação, principalmente na área arenizada, que, quando submetida às chuvas torrenciais, maximizaram os processos de erosão (FREITAS et al., 2009). 
Figura 9 - Distribuição de frequência absoluta e relativa dos meses-padrão na estação pluviométrica "Ponte do Miracatu", São Francisco de Assis/RS

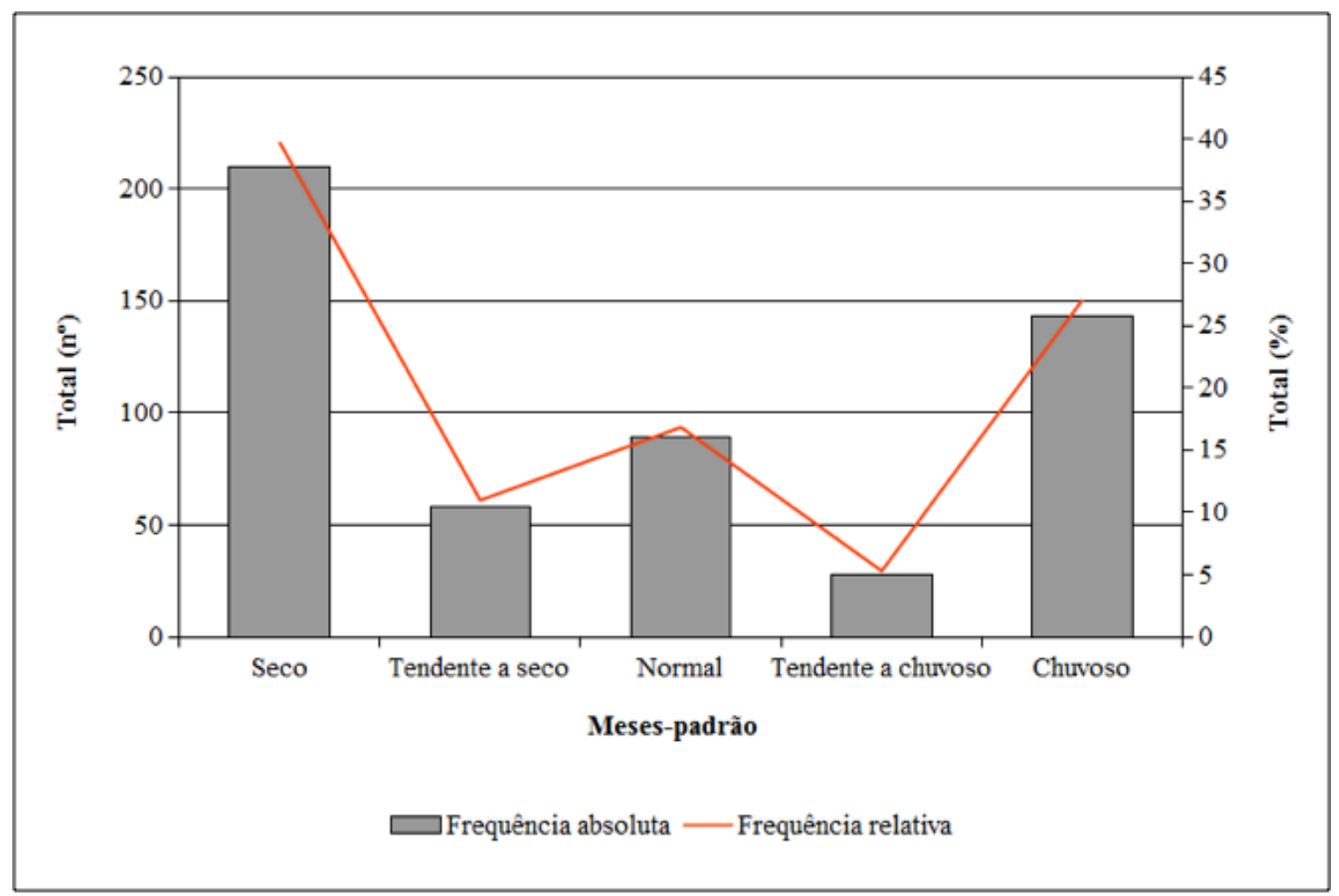

Fonte: ANA (1970-2013).

Verdum e Soares (2010), monitorando os processos erosivo-deposicionais em dois areais, observaram, do mesmo modo, que, no período de escassez de chuva, ocorreu a expansão das manchas arenosas, sobretudo devido à ação eólica. Por outro lado, durante os períodos com maior umidade e ocorrência de chuvas, os areais tendiam a se manter estáveis aos ventos, embora apresentassem elevada mobilidade dos sedimentos, porém, agora pelo escoamento superficial (VERDUM e SOARES, 2010).

Nota-se, pelas considerações trazidas por Scopel et al. (2012), Freitas et al. (2009) e Verdum e Soares (2010), que os meses considerados como secos ou tendentes a secos seriam, portanto, momentos onde imperariam a redução da cobertura vegetal e a desagregação dos solos/ formações superficiais, expondo o material sedimentar aos processos eólicos que participariam de uma importante remobilização dos friáveis sedimentos arenosos.

Esses sedimentos remobilizados e selecionados ficariam expostos à ação do escoamento superficial durante os meses chuvosos e tendentes a chuvosos. Isso pode- ria representar uma importante fonte de materiais carreados aos cursos d'água, sobretudo quando os processos de voçorocamento se encontram conectados à rede de drenagem fluvial, o que é uma situação comum na área de estudo. Ainda, cabe considerar, o potencial de remobilização dos sedimentos a partir da ação das águas subterrâneas quando desses fenômenos de chuvas torrenciais.

\section{CONSIDERAÇÕES FINAIS}

A definição dos anos e meses-padrão empregada neste trabalho contribuiu para a determinação quali-quantitativa, dos eventos pluviométricos extremos ocorridos em estação pluviométrica localizada, em uma das bacias hidrográficas (BHAM)que apresenta a maior ocorrência de processos de arenização (SUERTEGARAY, 1998; SUERTEGARAY et al., 2001). Os resultados demonstram elevada variabilidade anual e mensal, de tal modo que qualquer ano ou mês pode ser discri- 
minado em qualquer uma das classes empregadas.

Com isso, reforça-se a gênese dos areais, tendo como base a interação entre processos, inicialmente hídricos e, posteriormente eólicos, tal qual descrito por Suertegaray (1998). Além disso, destaca-se, novamente, a importância dos eventos excepcionais de chuva como elemento disparador dos processos superficiais e subterrâneos (VERDUM, 1997). É, portanto, da interação entre a fragilidade do meio, associada à dinâmica irregular das chuvas, onde anos e meses-padrão com características diferenciadas, ocorrem sucessivamente, ora potencializando ora minimizando os processos de arenização e justificando a natureza pulsante (expansão/retração) dos areais.

Por fim, é necessário salientar que os anos/meses-padrão observados neste trabalho refletem, claramente, a influência de fenômenos que se processam desde escalas interdecenais até interanuais, a exemplo da Oscilação Decadal do Pacífico (ODP), da Oscilação Multidecadal do Atlântico (OMA) e do El Niño Oscilação Sul (ENOS). Contudo, informações sobre a influência desses fenômenos na variabilidade das chuvas na área de estudo serão abordados futuramente.

\section{AGRADECIMENTOS}

Os autores agradecem ao Conselho Nacional de Desenvolvimento Científico e Tecnológico (CNPq) e a Fundação de Amparo à Pesquisa do Estado do Rio Grande do Sul (FAPERGS) pelo apoio financeiro relacionado aos projetos de pesquisa desenvolvidos entre os anos de 2012-2015. 
AYOADE, J.O (2010) Introdução à climatologia para os trópicos. 13. ed. Rio de Janeiro: Bertrand Brasil. 332p.

AZEVEDO, A.C.; KAMINSKI, J. (1995) Considerações sobre os solos dos campos de areia no Rio Grande do Sul. Ciência \& Ambiente, Santa Maria, v.11, p.65-70, jul./dez.

BARRIOS, N.A.Z.; HERNÁNDES, M.C.M. (1992) Aplicação de técnicas para escolha de anos-padrão, como base de estudo dinâmico das chuvas no extremo oeste paulista. Caderno Prudentino de Geografia, v.14, p.119-157.

BERTONI, J.C.; TUCCI, C.E.M. (2009) Precipitação. In: TUCCI, C.E.M. (Org.). Hidrologia: ciência e aplicação. 4.ed. Porto Alegre, RS: Editora da UFRGS/ABRH, p.177-241.

CAVALCANTI, I.F.A.; KOUSKY, V.E. (2009) Frentes frias sobre o Brasil. In: CAVALCANTI, I.F.A.; FERREIRA, N.J.; SILVA, M.G.A.J.; DIAS, M.A.F.S. (Orgs.).Tempo e clima no Brasil. São Paulo: Oficina de Textos, p.135-147.

DIAZ, A.F.; STUDZINSKI, C.D.; MECHOSO, C.R. (1998) Relationships between precipitation anomalies in Uruguay and Southern Brazil and sea surface temperature in the Pacific and Atlantic Oceans. Journal of Climate, v.11, p.251-271, fev.

FONTANA, D.C.; ALMEIDA, T.S. (2002) Climatologia do número de dias com precipitação pluvial no Estado do Rio Grande do Sul. Revista Brasileira de Agrometeorologia, Santa Maria, v.10, n.1, p.135-145.

FREITAS, E.M.; BOLDRINI, I.I.; MÜLLER, S.C.; VERDUM, R. (2009) Florística e fitossociologia da vegetação de um campo sujeito à arenizaçao no sudoeste do estado do Rio Grande do Sul, Brasil. Acta Botanica Brasilica, São Paulo, v.23, n.2, p.414-426, abr./jun.

GERARDI, L.H.O.; SILVA, B.C.N. (1981) Quantificação em Geografia. São Paulo: DIFEL. 161p.

GRIMM, A.M. (2009) Clima da região sul do Brasil. In: CAVALCANTI, I.F.A.; FERREIRA, N.J.; SILVA, M.G.A.J.; DIAS, M.A. F.S. (Orgs.). Tempo e clima no Brasil. São Paulo: Oficina de Textos, p.259-275.

HASENACK, H. (1981) Consequências da variabilidade pluviométrica no sudoeste do Rio Grande do Sul. Trabalho de conclusão de curso. Porto Alegre, RS: UFRGS/Geografia. $37 \mathrm{f}$.

LANNA, A.E. (2009) Elementos de estatística e probabilidades. In: TUCCI, C.E.M. (Org.). Hidrologia: ciência e aplicação. 4.ed. Porto Alegre, RS: Editora da UFRGS/ABRH, p.79-176.

LEOPOLD, L.B.; WOLMAN, M.G.; MILLER, J.P. (1964) Fluvial processes in geomorphology. San Francisco: Freeman andCo. $522 \mathrm{p}$.

MACHADO, F.P. (1950) Contribuição ao estudo do clima do Rio Grande do Sul. Rio de Janeiro: Instituto Brasileiro de Geografia e Estatística. 91 p.

MENDONÇA, F.A.; DANNI-OLIVEIRA, I.M. (2007) Climatologia: noções básicas e climas do Brasil. São Paulo: Oficina de Textos. 206p.

MONTEIRO, C.A.F. (1968) Clima. In: IBGE, Instituto Brasileiro de Geografia e Estatística. Geografia do Brasil: Grande região sul. v.IV, Série A, n.18, Rio de Janeiro: IBGE, p.114-166.

MONTEIRO, C.A.F. (1976) O clima e a organização do espaço no Estado de São Paulo: problemas e perspectivas. Série Teses e Monografias, n.28, São Paulo: IGEOG-USP. 54p.

MORENO, J.A. (1961) Clima do Rio Grande do Sul. Boletim Geográfico do Rio Grande do Sul, n.11, p. 49-83.

NERY, J.T. (1996) Estudio climático de la precipitación del Brasil Meridional asociado con fenómeno extrarregionales. Tese (Doutorado em Ciência da Atmosfera). Buenos Aires: Universidad de Buenos Aires/Facultad de CienciasExactas y Naturales. 138 p.

NERY, J.T. (2005) Dinâmica climática da região sul do Brasil. Revista Brasileira de Climatologia, v.1, n.1, p.61-75, dez.

NIMER, E. (1989) Climatologia do Brasil. 2.ed. Rio de Janeiro: IBGE/Depto. de Recursos Naturais e Estudos ambientais. $421 \mathrm{p}$. 
PETERSEN, J.F.; SACK, D.; GABLER, R.E. (2014) Fundamentos de Geografia Física. Tradução: Solange Aparecida Viscondi e Thiago Humberto Nascimento. São Paulo: Cengage Learning. 485 p.

ROSSATO, M.S. (2012) O clima no sudoeste do Rio Grande do Sul. In: SUERTEGARAY, D.M.A.; SILVA, L.A.P.; GUASSELLI, L.A. (Orgs.).Arenização : natureza socializada. Porto Alegre, RS: Compasso Lugar-Cultura/Imprensa Livre, p.385-411.

SANCHES, F.O. (2013) Os areais do sudoeste do Rio Grande do Sul: estudo sobre as chuvas no século XX e um possível cenário para o século XXI. Tese (Doutorado em Geografia). Porto Alegre: UFRGS/POSGEA. 188p.

SARTORI, M.G.B. (1993a) Distribuição das chuvas no Rio Grande do Sul e a variabilidade têmporo-espacial no período 1912-1984. Anais do V Simpósio Brasileiro de Geografia Física. São Paulo: Departamento de Geografia/FFLCH/USP, p.275-280.

SARTORI, M.G.B. (1993b) As variações pluviométricas e o regime das chuvas na região central do Rio Grande do Sul. Boletim de Geografia Teorética, v.23, p.45-46.

SCOPEL, I.; SUERTEGARAY, D.M.A.; SOUSA, M.S.; PEIXINHO, D.M.; FERREIRA, D.M. (2012) Neossolos quartzarênicos órticos das áreas de areais do sudoeste do Rio Grande do Sul: características físicas e morfológicas. In: SUERTEGARAY, D.M.A.; SILVA, L.A.P.; GUASSELLI, L.A. (Orgs.). Arenização: natureza socializada. Porto Alegre, RS: Compasso Lugar-Cultura/Imprensa Livre, p.503-540.

SERRA, A. (1969) Anos secos e chuvosos no Rio Grande do Sul. Boletim Geográfico, n.212, ano 28, p.37-74, set./out.

SUERTEGARAY, D.M.A. (1998) Deserto grande do sul: controvérsias. 2.ed. Porto Alegre, RS: Editora da UFRGS. 109p.

SUERTEGARAY, D.M.A.; GUASSELLI, L.A.; VERDUM, R. (Orgs.). (2001) Atlas da arenização: Sudoeste do Rio Grande do Sul. Porto Alegre, RS: Secretaria da Coordenação e Planejamento. 84p.

TEIXEIRA, M.S. Caracterização física e dinâmica de episódios de chuvas intensas nas regiões sul e sudeste do Brasil. (2010) Tese (Doutorado em Meteorologia). São José dos Campos: INPE/Programa de Pós-Graduação em Meteorologia. 167f.

VERDUM, R. (1997) L'approche géographique des «déserts» dans les communes de São Francisco de Assis et Manuel Viana, État du Rio Grande do Sul, Brésil. Tese (Doutorado em Geografia). Toulouse: UFR de Géographie et Aménagement, Université de Toulouse Le Mirail. $211 \mathrm{p}$.

VERDUM, R.; SOARES, V.G. (2010) Dinâmica de processos erosivos/deposicionais e microformas de relevo no interior dos areais, sudoeste do Rio Grande do Sul, Brasil. Revista de Geografia (UFPE), v.especial VIII SINAGEO, n.1, p.262-272, set.

VIANELLO, R.L.V.; ALVES, A.R. (2012) Meteorologia básica e aplicações. 2.ed. Viçoça, MG: UFV. 460p.

WOLLMANN, C.A.; SARTORI, M.G.B. (2009) Freqüência mensal e sazonal da participação de sistemas atmosféricos no verão do Rio Grande do Sul: análise sobre três casos típicos (1986/1987, 1997/1998 e 2004/2005). Ciência e Natura (UFSM), n.31, n.1, p.141-161.

ZAVATTINI, J.A.; BOIN, M.N. (2013) Climatologia geográfica: teoria e prática de pesquisa. Campinas, SP. Editora Alínea. 150p. 